\title{
Analysis of injury incidences in the Korea national men's soccer teams
}

\author{
Kwan Hwang-Bo', Chang-Hwa Joo ${ }^{2, *}$ \\ 'Department of Technical Education, Korea Football Association, Paju, Korea \\ ${ }^{2}$ Department of Sport Science, Kangwon National University, Chuncheon, Korea
}

The purpose of this study was to identify the frequency and characteristics of injuries that occurred during the training camps and matches of the national soccer teams (under-20 [U-20], under-23 [U-23], A men's national teams). The research data were based on injuries that occurred from January 2016 to December 2017. The athletic trainer, a member of the Korea Football Association, recorded injuries based on the recording sheet of the Asian Football Confederation Daily Medical Report. A total of 1,689 (984 in 2014; 705 in 2017) injuries were reported for the 2 years. Most injuries were sports injuries ( $95 \%$, sprains, etc.), and other conditions such as respiratory, digestive, and ocular, comprised only $5 \%$ of cases. The most injured areas of the national team players were the lower limbs $(85 \%, 1,366)$. The frequency of the head/trunk and upper ex- tremity injuries were relatively low $(8.4 \%, 135 ; 6.5 \%, 105)$. The frequency of injuries according to positions were as follows: midfielder $(40.3 \%, 648)$, defender $(36.6 \%, 688)$, forward $(17.8 \%, 286)$, and goalkeeper $(5.2 \%, 84)$. The most common types of injuries were contusions $(37.3 \%, 599)$, followed by muscle rigidity $(29.0 \%, 466)$ and sprains $(16.8 \%, 270)$. The characteristics of injuries amongst national soccer teams, according to age, were similar, but the injury characteristics for each position were different. Therefore, when organizing training programs for prevention and rehabilitation of athlete injuries and improvement of performance, it is necessary to consider the performance characteristics of each position.

Keywords: Soccer, National team, Injury

\section{INTRODUCTION}

Soccer is the most popular sport in the world with the largest number of participants (Dvorak et al., 2004). International competitions, such as the World Cup, have become more than just soccer matches between countries; they have evolved into sport events that affect society, culture, and the economy. Many countries invest excessive budgets in their soccer system and applying various methods to enhance the level of soccer. In Korea, since the early 2000s, the Korean government and several companies have invested a considerable amount of money to build soccer infrastructure for the 2002 Korea-Japan World Cup and for football development. The Korea Football Association (KFA) regularly convenes and trains age-specific soccer players of the national teams to improve their performance and strengthen international competitiveness using the improved soccer infrastructure.
The speed of modern soccer is considerably faster now than it was in the past. Consequently, soccer players are required to have a high level of physical fitness. In order to successfully complete a 90-min soccer match, the players must develop their fitness regarding endurance, strength, power, and speed, among others. Continuous high-intensity training during the training period without considering players' fitness levels and physical conditions may lead to injuries (Arnason et al., 2004). Injuries may result in an inability to participate in trainings and competitions which may, in turn, cause a decrease in exercise-related performance. While the injury recovery duration depends on the degree of the injury, a long-term rehabilitative training period is necessary to restore players to their preinjury performance level. Moreover, if the players are seriously injured, their rehabilitative training period may be longer and, in the worst case, they will not be able to continue the career as elite soccer players.
${ }^{*}$ Corresponding author: Chang-Hwa Joo (D) https://orcid.org/0000-0002-7429-3104 Department of Sport Science, Kangwon National University, 1 Kangwondaehak-gil, Chuncheon 24341, Korea

E-mail: ju217@hanmail.net

Received: October 9, 2019 / Accepted: November 11, 2019
This is an Open Access article distributed under the terms of the Creative Commons Attribution Non-Commercial License (http://creativecommons.org/licenses/by-nc/4.0/) which permits unrestricted non-commercial use, distribution, and reproduction in any medium, provided the original work is properly cited. 
Soccer is a sport in which physical contact with an opponent is permitted in order to win ball possession, and the nature of the game can potentially cause injury during training or competition. Soccer players suffer more injuries during games than training (Stubbe et al., 2015). Le Gall et al. (2006) reported that the incidence of lower limb injury is higher than that of other body parts and that the most common types of injury are sprains and strains. In addition, the reinjury rate of soccer players is $25 \%$ for all injuries, and reinjuries occur more commonly during training than in competition (Ergün et al., 2013). The most likely cause of reinjury is overuse of the injured area during prolonged training periods (Waldén et al., 2005).

The frequency and type of injuries incurred by football players can vary according to age group. Young soccer players are more likely to be injured compared to senior players, because they are still growing physically and their strength is not yet fully developed. Indeed, Pfirrmann et al. (2016) found that the incidence of injuries during $1,000 \mathrm{hr}$ of training and competition was significantly higher in young players than in senior players. Although many studies have been conducted on the injuries of young and adult soccer players (Bjørneboe et al., 2014; Brink et al., 2010; Dauty and Collon, 2011; Ergün et al., 2013), there are limited studies on the comparison of injury characteristics of top-level soccer players according to age groups, such as young and senior players of national teams.

The incidence of injuries experienced by soccer players also differs according to countries due to differences in playing styles and the regional climate (Waldén et al., 2013). Most studies on the incidence of injury among soccer players have been conducted mainly in European countries in which professional soccer leagues are well developed. There are few long-term studies on the frequency of injuries in soccer players in Korea and other Asian countries, and very little research has been conducted comparing the frequency of injury amongst the national team players according to age group. Therefore, the purpose of this study was to identify the frequency and characteristics of injuries that occurred during national soccer team training camps, categorized by age group, in order to provide data that could facilitate the prevention and rehabilitation of soccer players.

\section{MATERIALS AND METHODS}

\section{Subjects}

This study was based on data published by the Korea Football Association's Medical Team (kfamed.org). The medical staff re- corded injuries that occurred during the training and matches of the men's national teams according to age groups (U-20; U-1520, U-23; U-21-23, A national team) from January 2016 to December 2017.

\section{Measurements}

The injury characteristics were recorded by the athletic trainer (AT) of the KFA using the record sheet used by the Asian Football Confederation Daily Medical Report. The AT surveyed and recorded the type of injury, location of injury, location of injury by playing position, and diagnosis of injury that occurred during training or competition at the training camps for each age group. Injuries that occurred in teams other than the national teams were excluded from this study. To increase the reliability and accuracy of the injury record documented by each AT, the final decision was made after a review at the KFA Medical Team's regular meeting.

\section{Statistical analysis}

SPSS ver. 17.0 (SPSS Inc., Chicago, IL, USA) was used to perform frequency analysis and descriptive statistical analysis to determine the difference in injury characteristics by age groups.

\section{RESULTS}

\section{Type of injuries}

The frequency of injury of national team players by age was 1,689 injuries (984 injuries in 2016; 705 injuries in 2017) over 2 years. Most of the injuries were sports injuries ( $95 \%$, sprains, etc.), and only $5 \%$ were due to other conditions such as respiratory, digestive, and eye-related issues. Injury frequency, according to the type of injury, was similar between the 2 years assessed (Table 1).

\section{Location of injuries}

The most frequently injured location for the players based on age groups was the lower extremities, accounting for 85\% (1,366 injuries) of the total injuries. Head/trunk and upper limb injuries were relatively low at 8.4\% (135 injuries) and 6.5\% (105 injuries), respectively (Table 2).

Table 1. Types of injuries

\begin{tabular}{lccc}
\hline Type of injuries & 2016 & 2017 & Total \\
\hline Sports injuries & $934(94.9)$ & $672(95.3)$ & $1,606(95.1)$ \\
Other diseases & $50(5.1)$ & $33(4.7)$ & $83(4.9)$ \\
Total & 984 & 705 & 1,689 \\
\hline
\end{tabular}

Values are presented as number (\%). 


\section{Location of injuries by playing position}

The most frequently injured playing position for 2 years was midfielder (MF: 648 injuries, 40.3\%), followed by defender (DF: 588 injuries, 36.6\%), forward (FW: 286 injuries, 17.8\%), and

Table 2. Distribution of injuries in accordance with body part

\begin{tabular}{lccc}
\hline Body part & 2016 & 2017 & Total \\
\hline Head/trunk & $79(8.5)$ & $56(8.3)$ & $135(8.4)$ \\
Upper limb & $52(6)$ & $53(7.9)$ & $105(6.5)$ \\
Lower limb & $803(86)$ & $563(83.8)$ & $1,366(85.1)$
\end{tabular}

Values are presented as number $(\%)$. goalkeeper (GK: 84 injuries, 5.2\%). However, the number of injuries by position varied by year. In 2016, the most frequently injured playing position was MF (383 injuries, $41.0 \%$ ), followed by DF (316 injuries, 33.8\%), FW (191 injuries, 20.5\%), and GK (44 injuries, $4.7 \%$ ). However, in 2017, the most frequently injured playing position was DF (272 injuries, $40.5 \%$ ), followed by MF (265 injuries, 39.4\%), FW (95 injuries, 14.1\%), and GK (40 injuries, $6.0 \%)$. In all positions, the frequency of injury to the lower extremities (FW: 243 injuries [85.0\%], MF: 573 injuries [88.4\%], DF: 508 injuries [86.4\%], GK: 48 injuries [57.1\%]) was higher than that to the head/trunk region (FW: 28 injuries [9.8\%], MF:

Table 3. Distribution of injuries in accordance with body part across playing positions

\begin{tabular}{|c|c|c|c|c|c|c|c|c|}
\hline \multirow{2}{*}{ Body part } & \multicolumn{4}{|c|}{2016} & \multicolumn{4}{|c|}{2017} \\
\hline & FW & MF & DF & GK & FW & MF & DF & GK \\
\hline Head/trunk & $16(8.4)$ & $21(5.5)$ & $30(9.5)$ & $5(11.4)$ & $12(12.6)$ & $16(6.0)$ & $23(8.5)$ & $5(12.5)$ \\
\hline Upper limb & $10(5.2)$ & $18(4.7)$ & $13(4.1)$ & $12(27.3)$ & $5(5.3)$ & $20(7.5)$ & $14(5.1)$ & $14(35.0)$ \\
\hline Lower limb & $165(86.4)$ & 344 (89.8) & 273 (86.4) & $27(61.4)$ & $78(82.1)$ & $229(86.4)$ & 235 (86.4) & $21(52.5)$ \\
\hline Total & 191 & 383 & 316 & 44 & 95 & 265 & 272 & 40 \\
\hline
\end{tabular}

Values are presented as number ( $\%)$.

FW, forward; MF, midfielder; DF, defender; GK, goalkeeper.

Table 4. Distribution of diagnoses

\begin{tabular}{|c|c|c|c|c|c|c|c|}
\hline \multirow{2}{*}{ Diagnosis } & \multicolumn{3}{|c|}{2016} & \multicolumn{3}{|c|}{2017} & \multirow{2}{*}{ Total } \\
\hline & U-20 & U-23 & A team & U-20 & U-23 & A team & \\
\hline Concussion & $0(0)$ & $0(0)$ & $0(0)$ & $1(0.2)$ & $0(0)$ & $0(0)$ & $1(0.1)$ \\
\hline Fracture & $3(0.5)$ & $1(0.3)$ & $0(0)$ & $3(0.6)$ & $0(0)$ & $1(0.6)$ & $8(0.5)$ \\
\hline Stress fracture & $0(0)$ & $0(0)$ & $0(0)$ & $0(0)$ & $0(0)$ & $0(0)$ & $0(0)$ \\
\hline Dislocation/subluxation & $2(0.4)$ & $0(0)$ & $0(0)$ & $3(0.6)$ & $1(2.4)$ & $0(0)$ & $6(0.4)$ \\
\hline Tendon rupture & $0(0)$ & $0(0)$ & $0(0)$ & $0(0)$ & $0(0)$ & $0(0)$ & $0(0)$ \\
\hline Ligamentous rupture & $2(0.4)$ & $0(0)$ & $0(0)$ & $1(0.2)$ & $0(0)$ & $0(0)$ & $3(0.2)$ \\
\hline Sprain & $84(14.7)$ & $63(21.7)$ & $15(20.3)$ & $72(15.6)$ & $12(28.6)$ & $24(14.3)$ & 270 (16.8) \\
\hline Lesion of meniscus/cartilage & $1(0.2)$ & $0(0)$ & $0(0)$ & $0(0)$ & $0(0)$ & $0(0)$ & $1(0.1)$ \\
\hline muscle rupture & $1(0.2)$ & $0(0)$ & $1(1.4)$ & $1(0.2)$ & $0(0)$ & $1(0.6)$ & $4(0.2)$ \\
\hline Contusion/hematoma/bruise & $194(34.0)$ & $118(40.7)$ & $30(40.5)$ & 172 (37.2) & $19(45.2)$ & 66 (39.3) & 599 (37.3) \\
\hline Artiritis/synovitis/bursitis & $1(0.2)$ & $1(0.3)$ & $0(0)$ & $0(0)$ & $0(0)$ & $0(0)$ & $2(0.1)$ \\
\hline Tendinosis/tendinopathy & $22(3.9)$ & $1(0.3)$ & $0(0)$ & $8(1.7)$ & $0(0)$ & $2(1.2)$ & $33(2.1)$ \\
\hline Fasciitis/aponeurosis injury & $1(0.2)$ & $0(0)$ & $0(0)$ & $1(0.2)$ & $0(0)$ & $1(0.6)$ & $3(0.2)$ \\
\hline Impingement & $0(0)$ & $0(0)$ & $1(1.4)$ & $0(0)$ & $0(0)$ & $0(0)$ & $1(0.1)$ \\
\hline Laceratiion/abrasion/skin Lesion & $2(0.4)$ & $5(1.7)$ & $4(5.4)$ & $1(0.2)$ & $0(0)$ & $0(0)$ & $12(0.7)$ \\
\hline Abrasion & $6(1.1)$ & $2(0.7)$ & $2(2.7)$ & $7(1.5)$ & $0(0)$ & $4(2.4)$ & $21(1.3)$ \\
\hline Muscle rigidity & $193(33.9)$ & $54(18.6)$ & $14(18.9)$ & $149(32.3)$ & $8(19.0)$ & 48 (28.6) & 466 (29.0) \\
\hline Muscle cramps & $26(4.6)$ & $28(9.7)$ & $2(2.7)$ & $19(4.1)$ & $2(4.8)$ & $13(7.7)$ & $90(5.6)$ \\
\hline Muscle contusion & $14(2.5)$ & $5(1.7)$ & $1(1.4)$ & $3(0.6)$ & $0(0)$ & $0(0)$ & $23(1.4)$ \\
\hline Other & $18(3.2)$ & $12(4.1)$ & $4(5.4)$ & $21(4.5)$ & $0(0)$ & $8(4.8)$ & $63(3.9)$ \\
\hline Total & 570 & 290 & 74 & 146 & 42 & 168 & 1,606 \\
\hline
\end{tabular}

Values are presented as number $(\%)$. 
37 injuries [5.7\%], DF: 53 injuries [9.0\%], GK: 10 injuries [11.9\%]) and the upper limbs (FW: 15 injuries [5.2\%], MF: 38 injuries [5.9\%], DF: 27 injuries [4.6\%], GK: 26 injuries [31.0\%]). In the GK position, the highest frequency of injury was to the lower limbs, but this frequency was still lower compared to those in the other playing positions. Additionally, relatively high frequencies of upper limb and head/body trunk injuries were observed (Table 3).

\section{Diagnoses of injuries}

The most common diagnosis of injury amongst all age groups was contusions/hematomas/bruises, accounting for 599 recorded injuries (37.3\%) (U-20: 366 injuries [35.5\%], U-23: 137 injuries [41.3\%], A team: 96 injuries [39.7\%]), followed by muscle rigidity and sprains. Muscle rigidity accounted for 466 recorded injuries (29.0\%) (U-20: 342 injuries [33.1\%], U-23: 62 injuries [18.7\%], A team: 62 injuries [25.6\%]). Sprain accounted for 270 recorded injuries (16.8\%) (U-20: 156 injuries [15.1\%], U-23: 75 injuries [22.6\%], A team: 39 injuries [16.1\%]). This trend was similar for all age groups (Table 4).

\section{DISCUSSION}

This study was conducted to identify the frequency and characteristics of injuries incurred during national soccer team training camps, according to age group. The findings from the present study indicated that the frequency and injury characteristics were generally similar across all age groups.

Most of the injuries that occurred in national teams were sports injuries, and only $5 \%$ of injuries were related to other health conditions such as respiratory, digestive, and eye-related conditions. The results of a previous study that investigated the injury characteristics of youth soccer players over two seasons resulted in 320 sports injury-related injuries $(80 \%)$ and 82 other recorded conditions (20\%) (Brink et al., 2010). Although there are many reasons contributing to the different results between this study and our own studies, the different innate characteristics of the participants could be the main reason. Compared to the previous study where the authors surveyed elite, young soccer players in a Netherlands team, a certain number of players changed at each training camp in the present study. Players with injuries were excluded before the formal conclusion of the training camps in the present study. In addition, as only injuries that occurred during the training camp period were recorded, the number of sports injuries and other health conditions was lower than that in the previous study. Moreover, the incidence of sports injuries and other conditions in this study was similar across the years assessed.

The most frequently injured body part among national soccer players in Korea was the lower limbs, followed by the head/body trunk and upper limbs. These results are consistent with those of previous studies (Le Gall et al., 2006; Stubbe et al., 2015). The reason for many of the lower limb injuries in football players is related to the characteristics of the game. Although soccer players move only $1.2 \%-2.4 \%$ of the total game distance with the ball in a 90-min soccer match (Di Salvo et al., 2007), their skills require the use mainly of the lower extremities, especially the feet. In addition, soccer players intermittently perform high-intensity exercise such as sprinting, turning, jumping, landing, and tackling. These high-intensity movements cause fatigue in their lower extremities, and repeated fatigue is thought to cause injury to the lower extremities.

Overall, the most frequently injured playing position was MF, followed by DF, FW, and GK. These findings are supported by previous studies (Cloke et al., 2012; Deehan et al., 2007) which reported that the incidence of injuries in MF positions was higher compared to that of the other playing positions. These results may be closely related to the number of players in the playing position. Even if the number of players in the playing position varies, depending on the tactics of the soccer matches, generally, the numbers of players in the MF and DF positions are higher than those in the FW and GK positions. Therefore, the numbers of injured players in the MF and DF positions tend to be higher than those in the FW and GK positions.

The frequency of injury by playing positions differed slightly by year in this study. In 2016, the order of most frequent injuries according to playing positions was MF, DF, FW, and GK, whereas in 2017, it was DF, MF, FW, and GK. The annual differences observed over the 2 years may be due to the distinct characteristics of the players comprising the national teams. For example, the numbers of players in each playing position in a typical elite team will remain unchanged for 1 year. However, if there are players who the coaching staff would like to assess regarding their abilities of tactical understanding or skill performance, they tend to select players for training camps, regardless of the number of positions. Therefore, it seems that these difference by years occurred due to the difference in the numbers of players in the DF and MF positions participating in training camps. Unfortunately, the main limitation of this study is the failure to identify the annual number of players according to position in training camps. If the limitations of such studies are addressed in future studies, a more accurate incidence of injury based on playing position can be de- 
termined.

The frequency of injury to the lower limb was the highest in all positions, but the characteristic of injury was different in the GK position compared to the other playing positions. In the GK position, the number of upper limb and head/body injuries were relatively higher than those in the other playing positions. These results can be attributed to the exercise performance characteristics of the GK position. Unlike other positions, the characteristic of the GK players is greater use of the upper limbs during a match. For example, GK position players are more likely to injure their upper limbs and head/body trunks, because their hands and arms are in direct impact against the ground when they perform dives to save the ball.

The most common diagnoses of injury in this study were contusions/hematomas/bruises, muscle rigidity, and sprains. These findings were similar to international (Agel et al., 2007; Dick et al., 2007; Stubbe et al., 2015) studies that examined the diagnoses of injuries amongst soccer players. Injury in soccer players is related to the characteristics of the soccer match and the movement of the players during the game. As mentioned previously, soccer is a sport that allows intense physical contact with one's opponent during the match. This physical contact is the main cause of bruises incurred by players at various body parts. In addition, players must consistently perform excessive movements, such as turning, landing after a jump, and tackling, depending on the direction of the ball during the match, which can lead to a sudden strain of the muscles. Moreover, repetition of high-intensity running and excessive movement during a 90-min soccer match can result in muscle rigidity. Indeed, more injuries occur at the ends of the first and second halves of a game, since there is accumulation of fatigue during the soccer match (Ekstrand et al., 2011; Hawkins and Fuller, 1999). In addition, the accumulated fatigue and reduced muscle strength can cause sprains when players perform movements beyond the range of motion in the joint. Agel et al. (2007) indicated that the most common body part that is sprained amongst soccer players is the ankle.

In this study, the analysis of the characteristics of injuries in national soccer teams, determined by age groups, showed that the location, type, and diagnosis of injury was similar among the age groups. However, the type of injury by position differed according to the positional performance requirements. Therefore, in order to construct a training program for effective injury prevention, rehabilitation, and improvement of exercise performance for elite soccer players, it is necessary to consider the demands of exercise performance for the individual playing positions.
In future studies, if the injury characteristics of female elite soccer players are analyzed, it will be possible to provide important information for effective training management according to gender.

\section{CONFLICT OF INTEREST}

No potential conflict of interest relevant to this article was reported.

\section{ACKNOWLEDGMENTS}

This study was supported by 2019 Research Grant from Kangwon National University.

\section{REFERENCES}

Agel J, Evans TA, Dick R, Putukian M, Marshall SW. Descriptive epidemiology of collegiate men's soccer injuries: National Collegiate Athletic Association Injury Surveillance System, 1988-1989 through 2002-2003. J Athl Train 2007;42:270-277.

Arnason A, Sigurdsson SB, Gudmundsson A, Holme I, Engebretsen L, Bahr R. Risk factors for injuries in football. Am J Sports Med 2004;32(1 Suppl):5S-16S.

Bjørneboe J, Bahr R, Andersen TE. Gradual increase in the risk of match injury in Norwegian male professional football: a 6-year prospective study. Scand J Med Sci Sports 2014;24:189-196.

Brink MS, Visscher C, Arends S, Zwerver J, Post WJ, Lemmink KA. Monitoring stress and recovery: new insights for the prevention of injuries and illnesses in elite youth soccer players. Br J Sports Med 2010;44:809815.

Cloke D, Moore O, Shah T, Rushton S, Shirley MD, Deehan DJ. Thigh muscle injuries in youth soccer: predictors of recovery. Am J Sports Med 2012;40:433-439.

Dauty M, Collon S. Incidence of injuries in French professional soccer players. Int J Sports Med 2011;32:965-969.

Deehan DJ, Bell K, McCaskie AW. Adolescent musculoskeletal injuries in a football academy. J Bone Joint Surg Br 2007;89:5-8.

Di Salvo V, Baron R, Tschan H, Calderon Montero FJ, Bachl N, Pigozzi F. Performance characteristics according to playing position in elite soccer. Int J Sports Med 2007;28:222-227.

Dick R, Putukian M, Agel J, Evans TA, Marshall SW. Descriptive epidemiology of collegiate women's soccer injuries: National Collegiate Athletic Association Injury Surveillance System, 1988-1989 through 2002-2003. J Athl Train 2007;42:278-285.

Dvorak J, Junge A, Graf-Baumann T, Peterson L. Football is the most pop- 
ular sport worldwide. Am J Sports Med 2004;32(1 Suppl):3S-4S.

Ekstrand J, Hägglund M, Waldén M. Injury incidence and injury patterns in professional football: the UEFA injury study. Br J Sports Med 2011; 45:553-558.

Ergün M, Denerel HN, Binnet MS, Ertat KA. Injuries in elite youth football players: a prospective three-year study. Acta Orthop Traumatol Turc 2013;47:339-346.

Hawkins RD, Fuller CW. A prospective epidemiological study of injuries in four English professional football clubs. Br J Sports Med 1999;33: 196-203.

Le Gall F, Carling C, Reilly T, Vandewalle H, Church J, Rochcongar P. Incidence of injuries in elite French youth soccer players: a 10-season study. Am J Sports Med 2006;34:928-938.
Pfirrmann D, Herbst M, Ingelfinger P, Simon P, Tug S. Analysis of injury incidences in male professional adult and elite youth soccer players: a systematic review. J Athl Train 2016;51:410-424.

Stubbe JH, van Beijsterveldt AM, van der Knaap S, Stege J, Verhagen EA, van Mechelen W, Backx FJ. Injuries in professional male soccer players in the Netherlands: a prospective cohort study. J Athl Train 2015;50: 211-216.

Waldén M, Hägglund M, Ekstrand J. UEFA Champions League study: a prospective study of injuries in professional football during the 20012002 season. Br J Sports Med 2005;39:542-546.

Waldén M, Hägglund M, Orchard J, Kristenson K, Ekstrand J. Regional differences in injury incidence in European professional football. Scand J Med Sci Sports 2013;23:424-430. 